\title{
Tratamento endovascular das doenças da aorta: visão geral
}

\author{
José Honório PALMA, Enio BUFFOLO, Diego GAIA
}

As dissecções e aneurismas da aorta torácica constituem uma enfermidade de consequências por vezes catastróficas. Apesar dos avanços obtidos nos métodos diagnósticos, na técnica operatória, nos controles intra e pós-operatórios estas afecções ainda são um formidável desafio para os médicos envolvidos, principalmente cirurgiões, que têm que intervir nessa doença complexa e que, frequentemente, não permite erradicação completa.

O desafio do tratamento cirúrgico das dissecções aórticas e aneurismas precedeu, em décadas, à aventura dos cirurgiões em ousar intervir em cavidades cardíacas e como curiosidade, a primeira intervenção cirúrgica paliativa proposta para as dissecções foi realizada por Gurin et al. em um paciente que apresentava oclusão da artéria ilíaca direita por compressão da luz verdadeira pela falsa luz dilatada.

Nos últimos anos, importantes contribuições surgiram e uma das mais importantes foi o conceito pelo qual as doenças da aorta passaram a poder ser corrigidas por próteses endoluminares posicionadas no interior da aorta através de cateteres introduzidos na artéria femoral, sob controle radiológico. Basicamente, estes avanços foram introduzidos por Dotter et al. experimentalmente, em 1994, e Parodi et al., em 1996, já tratando alguns pacientes portadores de aneurismas da aorta abdominal, após extensos trabalhos experimentais

A dissecção da aorta descendente e os aneurismas que tanto assustava clínicos e cirurgiões pela altíssima taxa de mortalidade e morbidade quando complicados, encontrou na terapêutica endovascular uma opção muito interessante e assim surgiram os primeiros trabalhos na literatura com resultados animadores.

O objetivo da colocação da endoprótese na dissecção é a oclusão da lesão da íntima, impedindo desta forma que o sangue passe para a falsa luz e nos aneurismas é a exclusão do saco aneurismático da circulação e para isto fundamental que se tenha um diagnóstico preciso utilizando-se ecocardiograma, tomografia e arteriografia. Nestes novos tempos, a aortografia que se encontrava indicada no diagnóstico de poucos casos, se reabilitou, tendo em vista que todo este novo procedimento é realizado na sala de hemodinâmica (Figura 1).
O controle pós-operatório é feito na maioria das vezes por tomografia computadorizada, na qual procuramos observar a exclusão da falsa luz no caso de dissecções ou do saco aneurismático quando dos aneurismas verdadeiros (Figura.2)
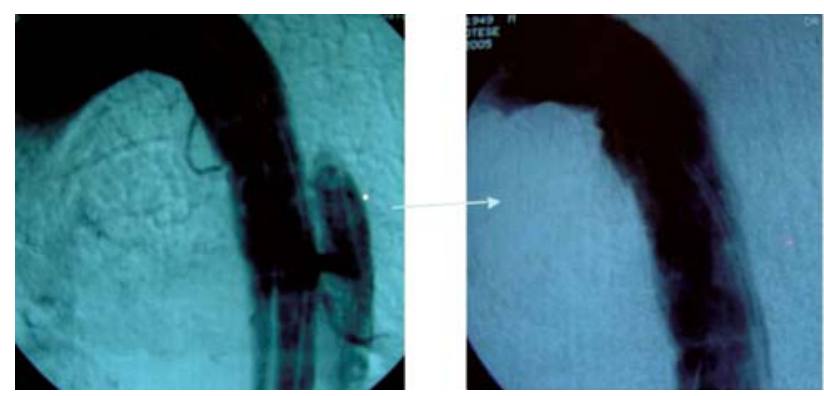

Fig. 1 - Arteriografia pré e pós-operatório de dissecção de aorta descendente demonstrando a exclusão da falsa luz após inserção do stent aórtico

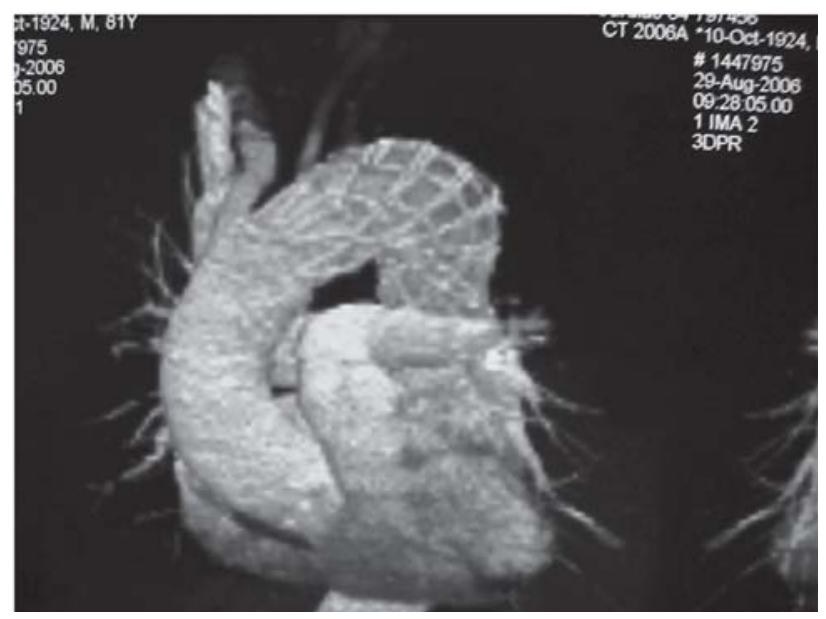

Fig. 2 - Controle pós-operatório demonstrando o stent bem posicionado se adaptando as curvaturas da aorta 
As vantagens desta nova intervenção têm sido demonstradas em diversas publicações recentes revelando menor agressão ao paciente por incisões reduzidas, a necessidade de entubação orotraqueal é por vezes desnecessária e as transfusões de sangue são feitas em menor quantidade. O tempo de internação e o tempo de terapia intensiva, por serem reduzidos, contribuíram para a redução importante dos custos. Estas mesmas publicações também demonstraram que esta nova opção terapêutica determina mais re-intervenções a médio e longo prazo.

Atualmente, devido à grande aceitação deste novo método, existem diretrizes para o tratamento endovascular das doenças da aorta descendente.

Ainda neste capítulo das endopróteses, uma das coisas mais interessantes foi o surgimento de diversas formas novas de abordar os segmentos da aorta utilizando os ditos procedimentos híbridos, onde o objetivo principal é simplificar, agredir menos o paciente, juntando uma operação clássica menor e um procedimento endovascular. Um dos exemplos principais nestas novas táticas é a oportunidade de solucionarmos um aneurisma ou dissecção do arco transverso realizando um enxerto bifurcado saindo da aorta ascendente e se dirigindo para o tronco braquiocefálico e para carótida e logo em seguida no mesmo ato, corrigirmos o aneurisma ou dissecção com stents aórticos evitando desta forma uma operação mais complexa onde necessariamente faríamos uso de hipotermia profunda e parada circulatória total [1].

\section{Passos práticos para o implante de endoproteses torácicas}

1- Estando o paciente na sua primeira visita para verificação da possibilidade do tratamento endovascular devemos inicialmente analisar a tomografia computadorizada com contraste endovenoso, a qual permitirá a observação de vários detalhes fundamentais a realização ou não do procedimento endovascular, levando em consideração que na prática diária tratamos hoje de forma rotineira os segmentos onde não saem ramos importantes da aorta, ou seja, aorta descendente, e aorta abdominal abaixo das artérias renais. Este exame serve para observarmos o colo proximal e distal, o tamanho do saco aneurismático, tortuosidades, calcificações e estenoses da própria aorta, assim como do sistema ilíaco-femoral. Nos casos de dissecções a variação dos ramos atingidos, a extensão na aorta e a identificação direta ou a suposição do local da ou das lesões são fundamentais no planejamento. A análise pormenorizada destes fatores determinara o sucesso do procedimento.

2- Os colos proximal e distal serão analisados observando-se principalmente se o diâmetro é adequado para o tratamento endovascular, ou seja, diâmetros compatíveis com tamanhos normais da aorta para aquela porção da aorta a ser tratada. Hoje, existem no mercado diversas endopróteses comerciais, cujo diâmetro atinge até 4.0-4.2 cm. Devemos levar em consideração que quando indicamos próteses com diâmetros destas proporções estamos ancorando-as em porções aneurismáticas da aorta, o que necessariamente não está errado quando estamos tratando doentes ou muito idosos ou com co-morbidades importantes, onde o resultado a longo prazo não esta em consideração. Ainda os colos podem adquirir formas diferentes, podem ser uma circunferência perfeita, podem ser ovais ou podem estar com a superfície interna irregular por placas de cálcio de diferentes tamanhos o que pode interferir na ancoragem com a determinação de vazamentos. No caso de dissecções da aorta, o diâmetro dos colos proximais deve ser determinado imediatamente antes da porção dissecada, normalmente junto a saída da artéria subclávia esquerda.

3- O diâmetro do saco aneurismático, assim como o diâmetro da falsa luz dilatada, importa muito na indicação da intervenção, pois sabemos da relação direta entre esta variável e a ocorrência de ruptura, porem não influi na escolha do diâmetro da endoprótese. Na realidade, os aneurismas e dissecções com diâmetros muito grandes podem, apesar de terem sidos tratados adequadamente, determinar compressões e ou distensões que por vezes mantêm o quadro álgico.

4- O sistema ilíaco femoral deve ser analisado delicadamente, pois os cateteres contendo as endopróteses serão passados por estes caminhos. As ilíacas podem ser tortuosas e com calcificações porem se forem calibrosas podemos prever que os cateteres passarão sem muita dificuldade o que não e verdadeiro se forem tortuosas, calcificadas e finas. As calcificações são vistas com facilidade pela tomografia e devem ser analisadas em conjunto com o exame físico, pois nos pacientes que tiverem grandes calcificações identificadas na tomografia associado a pulsos periféricos diminuídos podemos prever que as chances de que os cateteres passem sem dificuldades são pequenas.

5- As tortuosidades da própria aorta não dificultam a passagem dos cateteres, mas por outro lado aumentam o comprimento a ser tratado na medida em que devemos sempre ancorar as endopróteses em regiões retas tanto proximal quanto distal, permitindo assim que a força radial destas seja aplicada em toda a circunferência da aorta e não somente numa porção da parede. Por vezes, as tortuosidades são intensas na aorta abdominal e torácica e pela falta de comprimento do cateter não é possível atingir o colo proximal.

6- Nas dissecções agudas da aorta existe uma maior facilidade de passar os cateteres quando comparamos com procedimentos realizados em uma fase crônica, pois nesta última, com o passar do tempo, formam-se grandes 
dilatações e distorções com o aparecimento também de novas lesões de íntima, o que pode dificultar sobremaneira no momento de definirmos qual e a verdadeira e a falsa luz. A utilização do ecocardiograma transesofágico nas situações crônicas permite a identificação do caminho certo a ser seguido e do correto posicionamento dos cateteres na luz verdadeira.

7- A palpação dos pulsos femorais na primeira avaliação permite prever o grau de dificuldade que vamos encontrar durante a fase de inserção dos cateteres. Pacientes com pulsos ruins e fracos são candidatos pouco adequados para o tratamento endovascular, mesmo com o desenvolvimento recente de cateteres cada vez menos calibrosos e a escolha do lado a ser utilizado para a passagem dos dispositivos contendo as endopróteses deve ser feita levando-se em consideração o lado com pulso melhor.

8- A anestesia a ser utilizada deve se adequar a cada paciente, porém na maioria dos casos se podem realizar os procedimentos com bloqueio lombar, reservando-se a anestesia geral para os casos em que se vai utilizar o ecocardiograma transesofagico, pacientes muito agitados ou casos em que se prevê uma intervenção mais prolongada com muitas manobras. É possível realizar em casos selecionados anestesia local da região inguinal principalmente quando se pretende utilizar os dispositivos de oclusão percutânea da artéria femoral.

9- A base para realização dos procedimentos endovasculares sem dúvida é um fio guia rígido adequadamente posicionado servindo como trilho para a passagem de um ou mais cateteres dependendo da necessidade de cada caso. Este fator, quando associado a um calibre adequado das artérias femorais, permite prever o sucesso ou não do procedimento.

10- Quanto à liberação da endoprótese, o local de maior dificuldade, sem dúvida, é a porção inicial da aorta descendente junto ao arco, onde um posicionamento inadequado pode determinar a oclusão do tronco braquiocefálico mais raramente ou a carótida. Todos os dispositivos disponíveis no mercado são passíveis de uma liberação numa posição incorreta e para evitarmos este erro algumas manobras são realizadas, como, por exemplo, a injeção de contraste com o cateter já na posição de liberação e a utilização de um reparo anatômico para marcação da saída dos vasos. Distalmente, na atualidade, procuramos tratar principalmente nos caso de dissecção uma porção maior da aorta, atingindo por vezes a aorta junto ao diafragma. A oclusão durante a liberação proximal da artéria subclávia pode ser feita, sendo que o shunt pré ou pósoperatório deve ser realizado de acordo coma necessidade o que não deve ser feito distalmente com o tronco celíaco, pois neste vaso a interrupção do fluxo pode causar quadro clínico agudo e dramático.

11- A taxa de ocorrência de paraplegia, sem dúvida, é menor no tratamento endovascular, sendo obrigatória a percepção deste fenômeno imediatamente com conseqüente instalação de cateter para drenagem de líquor.

12- Os vazamentos, que são a grande limitação deste procedimento, devem ser tratados e a permanência destes significa principalmente que o paciente ainda permanece com o aneurisma ou dissecção com risco de apresentar complicações, entre elas a ruptura. Todo esforço deve ser feito para que o paciente saia da sala sem vazamentos e várias são as manobras passíveis de serem utilizadas, como, por exemplo, inserção de novas próteses proximais e ou distais, assim como dilatação das bordas das endopróteses com cateteres balões. Pacientes tratados desta nova forma necessitam de um acompanhamento constante, tendo em vista que, à semelhança dos stents de coronária, existe uma maior taxa de re- intervenção quando comparamos com os procedimentos cirúrgicos clássicos.

13- A necessidade de anti-coagulação nas intervenções torácicas se faz somente durante o procedimento, utilizando-se 5000UI inicialmente e acompanhando o tempo de coagulação ativado durante a realização do mesmo. Em pacientes com ruptura traumática da aorta, tendo em vista a possibilidade de lesões associadas, existe a possibilidade da inserção dos cateteres sem pinçamento das artérias e sem utilizarmos heparina.

14- Em relação às complicações do tratamento endovascular sabemos que iniciamos a prevenção das mesmas com um planejamento adequado do ato cirúrgico, análise dos diâmetros das artérias femorais, das ilíacas assim como dos colos proximais e distais. A prevenção destas intercorrências passa, sem dúvida, por uma análise detalhada dos exames prévios, a qual deve ser feita pela própria equipe que ira realizar o procedimento não confiando em mediadas já realizadas sem a visão endovascular da doença.

15- Em relação à tomografia, assim como a aortografia, existe a necessidade de deslocamento do doente grave para o local do exame. A tomografia dará uma idéia estática do acometimento da aorta em cortes longitudinais e transversais. A certeza do diagnóstico da dissecção em todas as séries de CT chega perto de 100\%, com a visibilização de dupla luz, embora existam relatos de casos tipo falso-negativos em uma pequena porcentagem. A tomografia não localiza a lesão da íntima, dado este de fundamental importância na programação cirúrgica, porém ela mostra a extensão da dissecção no sentido caudal da aorta, identificando casos com pequeno hemotórax, os quais significam uma iminência de ruptura. A tomografia dá também uma idéia espacial da aorta dissecada, através de seus inúmeros cortes transversais, baseados em pontos anatômicos fixos (esterno, coluna vertebral, artéria pulmonar, carina, diafragma, fígado e rins). Com este exame, consegue-se formar mentalmente uma idéia tridimensional 
de todas as porções da aorta, podem-se mensurar suas dilatações e ainda observar quais os órgãos ou estruturas acometidos por contiguidade. A tomografia helicoidal, de introdução recente, ainda em fase de consolidação, compõe as imagens dos cortes transversais e longitudinais, dando uma imagem de fácil interpretação.

16- O ecocardiograma tem se tornado um exame de suma importância e apresenta inúmeras vantagens: é um método barato, localiza com precisão a lesão da íntima na aorta ascendente, detecta se existe mais de uma lesão, bem como se existe o acometimento do arco transverso da aorta. Demonstra, ainda, o fluxo através da falsa luz e a formação de trombos. Vale lembrar também que este exame pode ser feito à beira do leito, sem que haja o deslocamento do paciente grave para fora da unidade de terapia intensiva, onde todos os seus parâmetros vitais estão controlados. A não utilização de contraste também é um fator a ser realçado, pois se sabe do grau de morbidade e mortalidade que a insuficiência renal pode acarretar. Quando se faz necessário o uso de contraste, o exame deve ser feito antes da aortografia, pois, localizando-se as lesões ou a lesão, com o ecocardiograma transesofágico, consegue-se diminuir a quantidade de contraste utilizado; assim, o médico responsável pela aortografia estará previamente orientado em relação ao local onde deve procurar as fendas. Além disso, o ecocardiograma analisa a função ventricular, como também a presença ou não de insuficiência aórtica ou hemopericárdio. Em alguns casos, a cirurgia foi realizada com o controle do ecocardiograma transesofágico e este procedimento é de fundamental importância, pois, realizado durante o procedimento, confirma os achados da véspera ou não, podendo-se, por exemplo, encontrar na dissecção tipo B um envolvimento da aorta ascendente por dissecção retrógada, fato este perfeitamente cabível, já que a dissecção é um processo dinâmico. O ecocardiograma intra-operatório dá oportunidade ao cirurgião de analisar o resultado da correção cirúrgica de imediato.

17- Já na aortografia, com a introdução do cateter por uma artéria, de preferência femoral, podem-se ter informações que os outros exames não mostram. Por exemplo, no estudo das artérias coronárias é possível evidenciar lesões coronárias passíveis de correção no mesmo tempo cirúrgico, ou avaliação de disfunção da valva aórtica também passível de correção conjunta. No entanto, a ocorrência de lesão coronária concomitante à dissecção aórtica não é tão comum, diferentemente da lesão valvar aórtica associada à dissecção. Este exame também mostra de forma dinâmica a situação da aorta distal, abdominal, podendo identificar a presença de outras lesões de íntima neste nível. O comprimento de vasos abdominais, assim como ilíacos, fica muito bem estabelecido por este exame. Existem relatos casos frequentes nos quais vasos abdominais ou ilíacos acabam tendo seus óstios saindo da falsa luz, o que leva o cirurgião a ficar sempre atento, pois existe a possibilidade de a correção endovascular realizada em nível torácico determinar isquemia aguda de algum órgão vital.

18- A experiência com a ressonância magnética está limitada aos pacientes que chegam ao hospital em uma fase mais crônica, estáveis, ou no controle dos casos submetidos à correção cirúrgica, tendo em vista a impossibilidade da realização deste exame em pacientes agitados e hemodinamicamente instáveis. A visualização da falsa luz se faz de maneira clara e mais recentemente podemos com este método diagnóstico acrescentar mais informações acerca de função ventricular, doença valvar associada e, por exemplo, áreas isquêmicas.

19- Feito o planejamento, as complicações se iniciam com a as punções e passagem de cateteres indo desde dissecções das artérias até ruptura das mesmas na região inguinal ou já na fossas ilíacas, sendo que o principal objetivo nestas situações de urgência é a realização do diagnóstico precoce seguido, então, dos procedimentos terapêuticos. Quando se conseguiu a passagem do fio guia, os sangramentos são de certa forma controlados ou pela passagem de um cateter balão proximal ao local de extravasamento ou a colocação de um stent recoberto.

20- A própria inserção e manipulação de cateteres no interior da aorta, principalmente no arco e em pacientes com aneurismas arterioscleróticos, pode por si só determinar acidentes neurológicos por deslocamento de placas calcificadas e a prevenção destes eventos vai deste a manipulação cuidadosa até a identificação destas estruturas pelo ecocardiograma transesofágico.

21- A ruptura da aorta é um acontecimento raro decorrente da manipulação no interior da aorta, porém existem casos relatados de dissecções retrógradas incluindo a aorta ascendente e há de se ter em mente que na maioria dos casos a doença da parede da aorta acomete toda a sua extensão, desde a aorta ascendente até sua bifurcação distal, mesmo que esta esteja manifestada por aneurisma e dissecção somente em um segmento.

22- A equipe deve estar preparada tecnicamente para resolver complicações maiores que colocam a vida do paciente em risco já durante a intervenção, a oclusão de ramos importantes como o tronco braquiocefálico e/ou a carótida esquerda deve ser inicialmente tratada com aumento da dose de heparina, seguida das manobras com cateter balão na tentativa de deslocamento da endoprótese no sentido distal. A realização de desvio cirúrgico deve ser feita com brevidade através da aorta ascendente ou da artéria carótida direita dependendo do vaso ocluído, quando as manobras descritas acima falharam.

23- Outra complicação grave, que pode ocorrer durante a liberação, é a formação de uma dobra (kinking) no corpo do stent, podendo determinar uma oclusão súbita da aorta com distensão do ventrículo esquerdo e finalizando com 
uma parada cardíaca. A manutenção de um fio guia corretamente posicionado através da endoprótese é fundamental, na medida em que se pode passar um cateter balão com consequente dilatação da área estenótica. Esta intercorrência pode ocorrer principalmente quando estamos tratando uma aorta de calibre pequeno (exemplo: pacientes com ruptura traumática da aorta).

24-Finalmente, existem limites para a as técnicas endovasculares, os quais, quando ultrapassados, podem determinar acidentes durante o procedimento. A equipe deve sempre pesar os riscos e benefícios deste novo procedimento contrapondo com as técnicas cirúrgicas clássicas e consagradas, nas quais os resultados são bem conhecidos. O procedimento endovascular deve ser simples, menos invasivo e menos agressivo. Novas técnicas, por exemplo, os procedimentos híbridos, que até bem pouco tempo atrás não existiam na literatura, pois surgiram em decorrência da visão endovascular, devem ser analisadas e carecem da apresentação dos resultados a médio e longo prazo para serem consolidadas ou não como alternativas viáveis.

\section{REFERÊNCIAS}

1. Albuquerque LC, Palma JH, Braile DM, Gomes W. Diretrizes para a cirurgia das doenças da aorta. Arq Bras Cardiol. 2004;82(supl. 5):35-50.

2. Turina MI, Shennib H, Dunning J, Cheng D, Martin J, Muneretto C, et al; EACTS/ESCVS Committee. EACTS/ESCVS best practice guidelines for reporting treatment results in the thoracic aorta. Eur J Cardiothorac Surg. 2009;35(6):927-30.

3. Svensson LG, Kouchoukos NT, Miller DC, Bavaria JE, Coselli JS, Curi MA, et al; Society of Thoracic Surgeons Endovascular Surgery Task Force. Expert consensus document on the treatment of descending thoracic aortic disease using endovascular stentgrafts. Ann Thorac Surg. 2008;85(1 Suppl):S1-41.

4. Raghupathy A, Nienaber CA, Harris KM, Myrmel T, Fattori $\mathrm{R}$, Sechtem U, et al; International Registry of Acute Aortic Dissection (IRAD) Investigators. Geographic differences in clinical presentation, treatment, and outcomes in type A acute aortic dissection (from the International Registry of Acute Aortic Dissection). Am J Cardiol. 2008;102(11):1562-6. 